\title{
Prospecção de Tecnologias Verdes com Foco em Gerenciamento de Resíduos
}

\author{
Prospecting Green Technologies With a Focus on Waste Management
}

\author{
Luiz Nunes Filho ${ }^{1}$ \\ Raimundo Nonato Macedo dos Santos ${ }^{1}$ \\ ${ }^{1}$ Universidade Federal de Pernambuco, Recife, PE, Brasil
}

\begin{abstract}
Resumo
A prospecção de tecnologias limpas contribui não só para o processo de planejamento e investimento em tecnologia com menor risco, como também consiste em uma questão de responsabilidade social. Tratar essa temática implica em averiguar como abrandar os problemas ambientais sem prejudicar o desenvolvimento tecnológico. Logo, investiga-se o desenvolvimento de tecnologias relacionadas ao gerenciamento de resíduos a partir dos resultados do Programa Patentes Verdes do INPI como forma de auxiliar no cumprimento dos objetivos da Política Nacional de Resíduos Sólidos. Para tanto, utiliza-se do método de abordagem qualitativo a partir de um procedimento exploratóriodescritivo em um corpus de 785 pedidos de Patentes Verdes. Neste sentido, por meio dos resultados revelados pela patentometria foi possivel verificar que a categoria de gerenciamento de resíduos é a de maior aplicabilidade ao Programa Patentes Verdes, com representação de 56,9\% dos pedidos deferidos pelo Programa, contribuindo, assim, para o desenvolvimento e aprimoramento de tecnologias limpas.
\end{abstract}

Palavras-chave: Prospecção. Programa Patentes Verdes. Gerenciamento de Resíduos.

\begin{abstract}
The prospecting of clean technologies contributes not only to the process of planning and investment in technology with less risk, it is also a question of social responsibility. To deal with this theme implies inquiring how to mitigate environmental problems without undermining technological development. Therefore, the development of technologies related to waste management is investigated based on the results from Green Patents Program of the INPI as a way to assist in the achievement of the National Solid Waste Policy objectives. To do so, the qualitative approach is used based on an exploratory-descriptive procedure in a corpus of 785 Green Patent applications. In this sense, through the results revealed by the patentometric analysis, it was possible to verify that the waste management category is the most applicable to the Green Patents Program, representing $56.9 \%$ of the requests granted by the Program, thus contributing the development and improvement of clean technologies.
\end{abstract}

Keywords: Prospection. Green Patents Program. Waste Management.

Área Tecnológica: Propriedade Intelectual. Prospecção Tecnológica. Patentometria. 


\section{Introdução}

O crescimento persistente do consumo pela sociedade tem impulsionado o aumento significativo da geração de resíduos, e a ausência de um gerenciamento adequado desses resíduos configura-se como um dos fatores preponderantes do aumento incontrolável da poluição do meio ambiente em escala global.

De acordo com Barbieri (1997, p. 139), as situações decorrentes da crise ambiental exigem "novas posturas em matéria de inovação tecnológica por parte da indústria que, por sua vez, dependem da condução de políticas públicas ambientais apropriadas".

Contudo, em que pese o papel de destaque dessas tecnologias para solução dos problemas ambientais, sabe-se que a contribuição não se fará por si só, isto é, em decorrência do seu simples desenvolvimento, pois é preciso que estejam suportadas por políticas públicas consistentes $e$ alinhadas com as necessidades ambientais dos ecossistemas em que estão inseridas.

Dentre os diversos instrumentos de políticas públicas elaboradas no Brasil, está a Lei Federal n. 12.305, de 2010, que instituiu a Política Nacional de Resíduos Sólidos (PNRS) com o objetivo de estabelecer diretrizes relativas ao gerenciamento dos resíduos sólidos (BRASIL, 2010).

Entretanto, mesmo sob a égide de uma extensa legislação ambiental, esta tem seu foco em ferramentas de comando e controle, de maneira que, são fixados padrões ambientais para que se possa fiscalizar seu cumprimento. No entanto, pelo que se observa, esse não é o melhor cenário para desenvolvimento de ações de inovação tecnológica, muito embora a Política Nacional do Meio Ambiente, instituída pela Lei n. 6.938, de 1981, manifeste esta finalidade expressamente. O fato é que, sem estímulos de mercado, as organizações não se sentem motivadas para a busca de situações tecnologicamente melhores para o meio ambiente (BARBIERI, 1997).

Esses atributos da política ambiental brasileira possivelmente estão associados à dificuldade de implementação das tecnologias verdes por parte das organizações. Portanto, tendo em vista que a divulgação desse tipo de tecnologia é crucial para o processo de desenvolvimento econômico e ambiental, ações estratégicas envolvendo propriedade intelectual se apresentam como importante vetor para a propagação das tecnologias verdes no mercado.

Logo, observa-se a patente como privilégio temporário concedido pelo Estado, que se caracteriza por atribuir ao seu titular o direito exclusivo de exploração da tecnologia patenteada e, em contrapartida, o Estado a torna pública (BARBOSA, 2010).

Assim, na medida em que as informações patentárias públicas podem fundamentar a criação de novas tecnologias para sociedade, o Instituto Nacional da Propriedade Industrial (INPI), aliado aos propósitos da Política Nacional sobre Mudança do Clima (PNMC) - na forma da Lei n. 12.187 de 2009 - lançou o Programa Patentes Verdes, inspirado em programas semelhantes já em vigor em outros países.

De acordo com Santos (2016), o programa tem por objetivo acelerar o exame dos pedidos de patentes relacionadas às tecnologias verdes e consequentemente reduzir o prazo para sua concessão, bem como identificar tecnologias estratégicas para que o Brasil atenda às ações de mitigação do efeito estufa estabelecidas pela PNMC.

O Programa Piloto Patentes Verdes foi posto em execução em 2012 por meio da Resolução n. 283/2012 do INPI e desde novembro de 2016 faz parte dos serviços permanentes da 
autarquia por meio da Resolução n. 175/2016 do INPI, que disciplina o exame prioritário dos pedidos de patentes de tecnologias verdes (INPI, 2012; 2016).

Para delimitação do escopo do programa tomou-se por base as áreas tecnológicas descritas no Inventário Verde da Organização Mundial da Propriedade Intelectual (OMPI), com exceção das áreas administrativas, regulamentadoras ou aspectos de design e geração de energia nuclear, sendo contempladas pela resolução do INPI apenas as seguintes áreas: energias alternativas; transportes; conservação de energia; gerenciamento de resíduos; e agricultura (INPI, 2012).

Nessa perspectiva, a realização de pesquisas de monitoramento ou estudos de prospecção tecnológica em patentes podem contribuir para identificar o estado da técnica de uma inovação, mapear cenário futuro, traçar tendências tecnológicas, bem como identificar stakeholders (inventores, investidores, universidades, instituições de pesquisa) com interesse em determinadas áreas tecnológicas.

Assim, a disseminação de inovações tecnológicas limpas por meio de um estudo de prospecção contribui para o processo de planejamento $e$ investimento em tecnologia com menor risco, tornando-se base para a tomada de decisão dos investidores e das organizações com interesse em Pesquisa e Desenvolvimento - P\&D. Além do mais, trata-se de uma questão de responsabilidade social, uma vez que o investimento em meio ambiente implica em melhores resultados no Índice de Desenvolvimento Humano (IDH) e no índice de desenvolvimento econômico do país.

Nesse contexto, a pesquisa aborda as tecnologias verdes relacionadas ao gerenciamento de resíduos como forma de auxiliar no cumprimento dos objetivos da PNRS.

Dessa forma, alguns questionamentos são feitos: Qual a aplicabilidade da área de gerenciamento de resíduos, no âmbito do Programa Patentes Verdes do INPI? Quais tecnologias estão sendo desenvolvidas nesta área? Qual o perfil dos depositantes desta categoria?

Para responder a esses questionamentos a presente pesquisa inclina-se em mapear informações tecnológicas contidas em documentos de patentes deferidas e relacionadas ao gerenciamento de resíduos a partir dos resultados do Programa Patentes Verdes do INPI.

Vê-se que as tecnologias aqui tratadas visam à promoção do novo padrão idealizado de desenvolvimento, denominado pela Comissão Mundial sobre Meio Ambiente e Desenvolvimento (1988) de: "desenvolvimento sustentável".

Sendo assim, demonstrada a relevância da temática abordada, a presente pesquisa prioriza a análise de pedidos de patentes verdes com foco em gerenciamento de resíduos, dada a importância dessa categoria para auxiliar no cumprimento dos objetivos traçados pela PNRS e pela alta aplicabilidade da categoria ao Programa Patente Verdes, tendo em vista que, já na primeira fase do programa piloto, a área de gerenciamento de resíduos foi a de maior destaque, representando $37 \%$ dos pedidos de patente deferidos, de acordo com estudo publicado por Menezes, Santos e Bortoli (2016).

Para alcance dos fins abalizados nesta pesquisa, o trabalho está dividido em 5 (cinco) seções. A primeira seção é constituída pela presente introdução.

Na segunda seção consta a revisão da literatura acerca do modus operandi de prospecção tecnológica em documentos de patente. 
Os procedimentos metodológicos e o mapeamento das informações tecnológicas dos pedidos de patentes do Programa Patentes Verdes são apresentados na terceira e na quarta seção, respectivamente.

Por fim, na quinta e última seção sintetizam-se as principais questões abordadas ao longo desta pesquisa, com destaque para aspectos considerados relevantes para a compreensão do panorama nacional das tecnologias verdes de gerenciamento de resíduos.

\section{Revisão da Literatura}

Está cada vez mais comum o uso de informações patentárias em análises econômicas para mensurar o desempenho de organizações, instituições de pesquisa ou universidades.

Para Maricato, Noronha e Fujino (2008, p. 4) "as patentes possuem características e propriedades que a torna uma fonte de informação extremamente útil para atividades relacionadas à busca e análise de informações jurídicas, econômicas e tecnológicas" tendo em vista que as informações técnicas contidas em documentos de patentes, muitas vezes ainda não se encontram disponíveis em livros ou artigos científicos.

Assim, a patente se revela como importante recurso tanto no desenvolvimento de atividades científicas e tecnológicas quanto nas práticas relacionadas à gestão. No âmbito do desenvolvimento científico e tecnológico a patente representa vantagem indispensável no desenvolvimento de novas tecnologias (GARCIA, 2006).

Também de acordo com Garcia (2007, p. 55), a patente constitui "um indicador de desenvolvimento entre países, a patente é instrumento de poder, estabelece um fosso entre países centrais e periféricos" de modo que por meio do estudo de informações patentárias mensura-se o nível de desenvolvimento tecnológico de uma população, bem como se permite avaliar os impactos econômico, social e até mesmo ambiental das tecnologias.

Já no campo empresarial as informações tecnológicas extraídas dos documentos de patentes representam diferencial para as organizações que têm $\mathrm{P} \& \mathrm{D}$ como estratégia competitiva, considerada, para Maricato, Noronha e Fujino (2008), exploração de conteúdo informacional útil para a escolha das melhores alternativas estratégicas disponíveis, propiciando maior vantagem competitiva às empresas.

O acesso dessas informações é possível por meio de consultas aos bancos de dados dos escritórios de patentes ou por meio dos bancos de dados comerciais disponíveis no mercado que possibilitam consultas mais completas e com ferramentas de busca mais flexíveis.

Essas bases apresentam mecanismos de busca para recuperação de dados nos documentos de patente que facilitam o acesso às informações tecnológicas e, assim, possibilitam o mapeamento tecnológico, sendo possível identificar a origem da tecnologia (país ou região), titulares, autores, instituições, áreas da ciência, e uma diversidade de predicados que contribuem para a difusão do conhecimento e da inovação.

É possível a recuperação dessa vasta gama de informações, pois a folha de rosto dos documentos de patente é estruturada de acordo com um padrão internacional, por meio do qual se identificam dados bibliográficos e técnicos enumerados por códigos internacionais de identificação, chamados de Códigos INID - Internationally agreed Numbers for the Identification 
of Data - que são disponibilizados pela OMPI, no standard ST.9, de modo que a busca pode ser feita independentemente da língua em que esteja escrito o documento de patente.

Percebe-se que, no universo das patentes, faz-se necessária a utilização de mecanismos capazes de organizar e categorizar as tecnologias, de maneira que tornem a recuperação das informações viável. Neste sentido, a Classificação IPC - International Patent Clasification, ou em livre tradução, Classificação Internacional de Patentes, identificável nos documentos pelo Código INID: 51 desempenha papel fundamental nas estratégias de busca por campo tecnológico.

A Classificação Internacional de Patentes trata-se de um acordo firmado no ano de 1971 em Estrasburgo e que está em vigência desde 1975. Coordenada pela OMPI, a IPC é adotada por mais de 100 países, incluindo o Brasil. Anualmente revisada em razão do desenvolvimento técnico e científico, está disponível em vários idiomas, inclusive em português (WIPO, 2019).

De acordo com o INPI (2019), a classificação objetiva estabelecer uma ferramenta de busca eficaz que possibilite a recuperação de documentos de patentes pelos escritórios de propriedade intelectual e demais usuários, com a finalidade de estabelecer a novidade e avaliar a atividade inventiva.

Assim, a principal finalidade dessa classificação é possibilitar uma pesquisa sistemática de informações patentárias, pois facilita, por exemplo, o acesso a informações tecnológicas e legais em campos tecnológicos específicos, uma vez que a classificação se dá por meio de um sistema hierarquizado de símbolos que distribui as tecnologias por categorização de áreas.

Inicialmente, a ferramenta de classificação está dividida em oito seções (WIPO, 2019) que representam o primeiro nível hierárquico da subdivisão e que categorizam o conhecimento humano voltado para a tecnologia da seguinte forma:

a) Seção A - Necessidades humanas;

b)Seção B - Operações de processamento e Transporte;

c) Seção C - Química e Metalurgia;

d)Seção D - Têxtil e Papel;

e) Seção E - Construções fixas;

f) Seção F - Engenharia Mecânica, iluminação, aquecimento, armas, explosão;

g) Seção G - Física;

h)Seção H - Eletricidade.

Por sua vez, tais seções estão segmentadas em classes, subclasses, grupos e subgrupos, e por meio desse tipo de classificação é possível recuperar documentos de patentes em quaisquer países que utilizem a IPC, viabilizando estudos de prospecção cada vez mais abrangentes e com informações mais precisas.

Portanto, a prospecção tecnológica em documentos de patente consiste na realização de análises a partir de estudos métricos da informação, especialmente por meio de aplicação da técnica de patentometria.

Para Sánchez (1999), é por meio da análise patentométrica que se mensura o grau tecnológico e de inovação de um país ou de um setor industrial, além de permitir a transformação do conhecimento científico em conhecimento tecnológico aplicado. 
Assim, a patentometria possibilita conhecer a atividade tecnológica, traçar tendências, monitorar pesquisas científicas, avaliar os resultados oriundos do investimento em P\&D e até mesmo verificar o grau de inovação em determinadas áreas, regiões e instituições, sendo também a técnica de estudo infométrico com maior possibilidade de aproximar instituições acadêmicas com a iniciativa privada (SÁNCHEZ, 1999; PEREIRA, 2008).

Pela vasta quantidade de informações extraídas por meio do uso da técnica da patentometria, Narin, Breitzman e Thomas (2005) considera a análise de patentes como um instrumento para auxiliar no investimento em inovação, tendo em vista que os indicadores apresentam aplicação em nível empresarial estratégico, sendo utilizados em estudos de diversos setores na indústria.

Dessa forma, a patentometria pode ser considerada como valiosa ferramenta de inteligência competitiva no âmbito da ciência e inovação, servindo, portanto, de aporte metodológico para subsidiar estudos de prospecção tecnológica, inclusive, com potencial para avaliar a relação do desenvolvimento tecnológico com outros campos do conhecimento, a exemplo, do meio ambiente.

\section{Metodologia}

Para o estudo, foi realizada uma pesquisa de abordagem qualitativa com análise de dados quantitativos a partir de um procedimento exploratório-descritivo em fontes de informação tecnológica disponíveis em um banco de dados de patentes, de modo que os processos se deram por meio da busca e análise de dados em documentos de patentes.

Quanto aos fins, a pesquisa apresenta caráter exploratório e descritivo. É considerada exploratória, pois explora alternativas úteis para diagnosticar situações, na medida em que gera mais informações que podem ser adquiridas para a realização de futuras pesquisas conclusivas (ZIKMUND, 2000). Por sua vez, é considerada descritiva tendo em vista que visa a descrever as caraterísticas de determinada população ou fenômeno (GIL, 1999).

Dessa maneira, o estudo teve seu foco em informações tecnológicas disponíveis na base de dados de patentes do INPI, por ser esse o escritório responsável pela concessão de patentes no Brasil. O universo da pesquisa compreende patentes de tecnologias verdes relacionadas ao gerenciamento de resíduos, depositadas e deferidas por meio do exame prioritário disciplinado pelo Programa Patentes Verdes.

Levando-se em conta os procedimentos técnicos, foi realizada uma pesquisa de cunho documental, por meio da análise de dados secundários, em documentos pertencentes ao local estudado, mesmo que já existisse um tratamento analítico (ZANELLA, 2011).

Por conseguinte, para a análise dos documentos de patentes relacionadas às tecnologias verdes foi utilizada a técnica da patentometria, que consiste em identificar tecnologias e atividades de inovação por meio do estudo de informações tecnológicas contidas em documentos de patentes (SÁNCHEZ, 1999). Dessa forma, é possível identificar titulares, áreas de classificação, setores econômicos, regiões, bem como o estado da técnica, visto que é possível identificar patentes de anterioridade.

O corpus da pesquisa compreende pedidos de patentes protocolados no INPI com código do serviço 279 , isto é, que apresentam formulário de solicitação para o exame prioritário do 
Programa Patentes Verdes. Tais pedidos foram protocolados no período entre $1^{\circ}$ de abril de 2012, por ser este o marco inicial do Programa Piloto Patentes Verdes no Brasil, até 11 de abril de 2019, data em que foi gerado o Protocolo Automatizado Geral dos pedidos de Patentes Verdes, fornecido via e-mail pela Chefia de uma Unidade Regional do INPI com respaldo na Lei n. 12.527/2011, que regula, dentre outras situações, o acesso a informações relativas ao serviço das autarquias (BRASIL, 2011).

Como estratégia de pesquisa para recuperação dos documentos de patentes, foram coletados os dados por meio da opção "busca de patentes" no site do INPI, aplicando-se o Sistema Busca Web (base de patentes do INPI). Em seguida, na opção "Contenha o No do Protocolo" foi inserido o respectivo número de protocolo de cada pedido constante na lista do Protocolo Automatizado Geral dos pedidos de Patentes Verdes.

Dessa forma, cada pedido foi analisado individualmente, de modo que para a identificação da área tecnológica verde consultou-se em cada pedido a análise da solicitação para o exame prioritário do Programa Patentes Verdes. Assim, foram selecionados e analisados os pedidos deferidos na área de gerenciamento de resíduos por serem estes o objeto de estudo da pesquisa.

Para análise de outros dados necessários ao estudo de prospecção como, por exemplo: classificação, titular, data do depósito e concessão da patente, foram extraídas informações da tela inicial de Consulta à Base de Dados do INPI de cada patente verde.

Importante mencionar que a análise das informações extraídas da base de patentes do INPI foi realizada durante o mês de maio de 2019, de modo que se esta metodologia for aplicada ao mesmo corpus posteriormente pode apresentar alguns resultados diversos dos aqui expostos, uma vez que vários processos continuam em trâmite no INPI e podem mudar de status conforme o avanço nos exames dos pedidos de patentes.

Ressalta-se ainda, que se fez uso da ferramenta computacional, Microsoft Excel, para apoiar a construção de tabelas e gráficos para que assim fosse possível verificar a aplicabilidade da área de gerenciamento de resíduos ao Programa Patentes Verdes, bem como representar a contribuição destas tecnologias para o cumprimento das diretrizes da PNRS e, consequentemente, para sustentabilidade do meio ambiente.

\section{Resultados e Discussão}

No corpus, consta a totalidade de 785 pedidos com solicitação para participação do programa, em que estão inseridas, além do código 279 , outras informações como número do protocolo, por meio do qual é possível acessar o trâmite de cada pedido de patente na base de dados do INPI.

Assim, dos 785 pedidos apenas três tiveram a análise prejudicada por não estarem regularmente acessíveis na base do INPI, de modo que foi possível identificar o status de movimentação em 782 pedidos com solicitação de patente verde.

Dessa maneira, verificou-se a existência de 274 pedidos deferidos, 201 pedidos indeferidos, 129 pedidos em processamento, 105 pedidos não aptos, 51 pedidos arquivados e 22 pedidos com numeração anulada, conforme se apresenta na Figura 1. 
Figura 1 - Status dos pedidos de Patentes Verdes no INPI

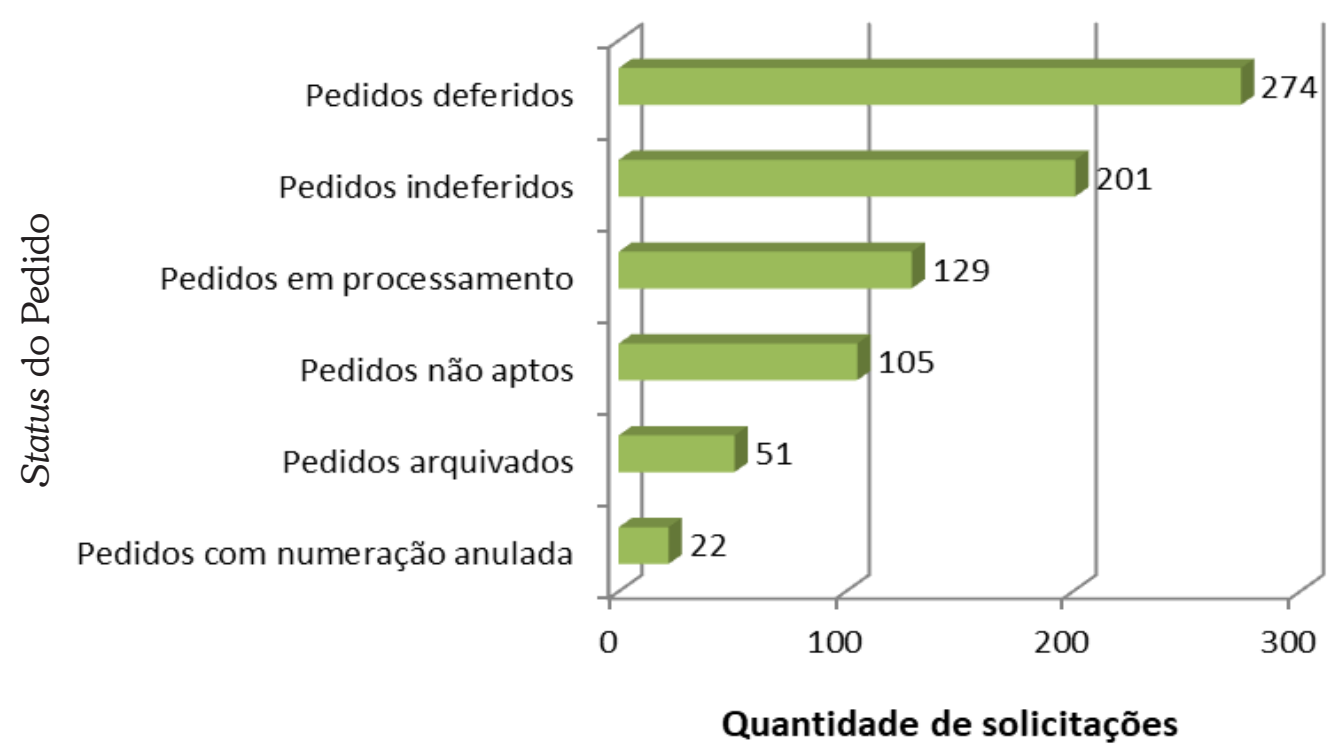

Fonte: Elaborada pelos autores deste artigo com base em dados extraídos do INPI (2019)

A título de esclarecimento, os pedidos deferidos são aqueles que preencheram os requisitos necessários para a patenteabilidade; indeferidos aqueles que não obtiveram êxito e, consequentemente, não será concedida a patente; pedidos em processamento são os que estão em trâmite no INPI e ainda não possuem uma decisão de mérito; pedidos não aptos são aqueles que não se encaixam nos requisitos descritos na Resolução do INPI para o exame prioritário do Programa Patentes Verdes; pedidos arquivados são os que, por algum motivo legal, tiveram seu processamento interrompido sem resolução de mérito como, por exemplo, a falta de pagamento de anuidade e; por fim, os pedidos com numeração anulada são aqueles que não atenderam a uma exigência formal do INPI.

Quanto às categorias de tecnologias verdes, de acordo com a Resolução n. 175/2016, estas estão divididas em cinco categorias baseadas no Inventário Verde publicado pela OMPI. Desta forma, dos 782 depósitos analisados manualmente, 234 desses não foi possível identificar a categoria por diversos motivos, dentre eles, pelo fato de a tecnologia não se enquadrar no escopo da Resolução do INPI e, portanto, ser considerada não apta, por ser arquivada antes da análise da admissão do exame de prioridade, por ainda não haver pronunciamento do INPI nesse sentido, ou simplesmente por não ter sido especificada nos anexos disponibilizados na base de dados.

Desta forma, foi possível identificar a categoria de tecnologias verdes em 548 depósitos de patentes, no entanto, vale salientar que 51 dessas tecnologias foram classificadas em duas categorias simultaneamente, de modo que para verificação do número de solicitações por categoria de tecnologias verdes, essas foram contabilizadas duas vezes, ou seja, uma vez em cada categoria em que foi classificada.

Sendo assim, a Figura 2 apresenta a seguir o número de solicitações por categoria de tecnologias verdes. 
Figura 2 - Número de solicitações de patentes por categoria de tecnologias verdes

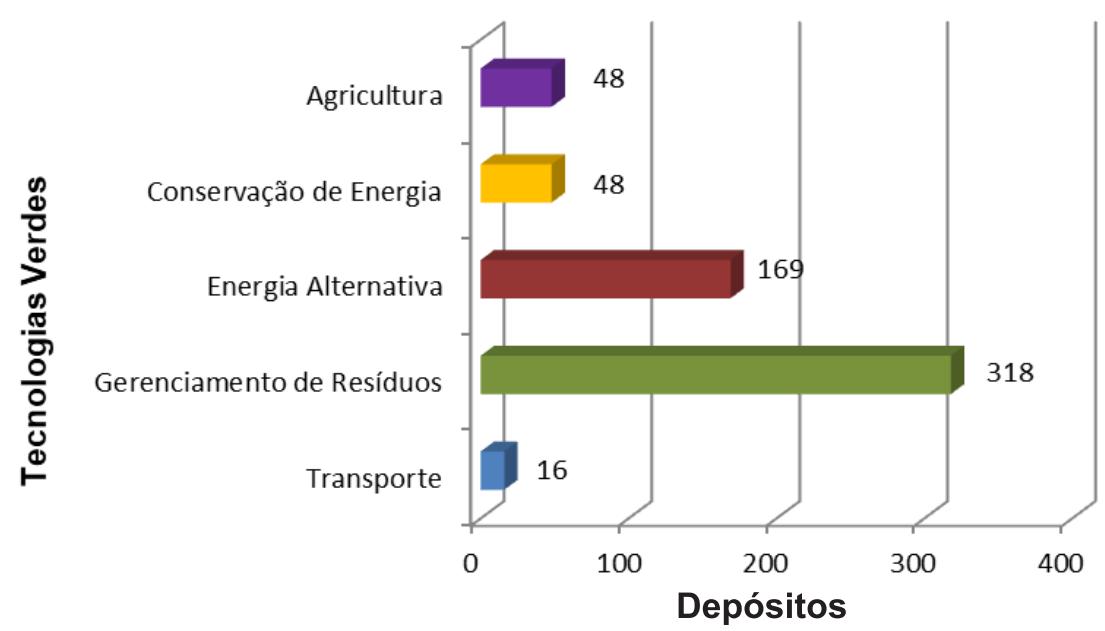

Fonte: Elaborada pelos autores deste artigo com base em dados extraídos do INPI (2019)

A Figura 2 demonstra que a categoria de gerenciamento de resíduos foi a de maior destaque em número de solicitações com 318 depósitos, fato que corrobora a relevância do foco da pesquisa nessa categoria. Na sequência, apresenta-se a categoria de energia alternativa com 169 depósitos, seguida das categorias agricultura e conservação de energia com 48 depósitos cada uma e, por fim, a categoria de transportes com apenas 16 depósitos de pedidos de Patentes Verdes.

Esses depósitos de patentes, ora analisados por categoria, encontram-se em diferentes status de movimentação no INPI, desta forma, dentre os 548 depósitos, então em análise, estão pedidos deferidos, indeferidos, em processamento e arquivados.

Tendo em vista que o objeto principal deste estudo são as tecnologias deferidas na categoria de gerenciamento de resíduos, foi dada ênfase aos 318 depósitos de patentes nessa categoria com a intensão de verificar quantas já foram deferidas e assim mapear o desenvolvimento de tecnologias verdes em gerenciamento de resíduos no Brasil.

Portanto, a Figura 3, a seguir, apresenta o status de movimentação no âmbito do INPI dos depósitos da categoria de gerenciamento de resíduos.

Figura 3 - Status dos pedidos de Patentes Verdes em Gerenciamento de Resíduos no INPI

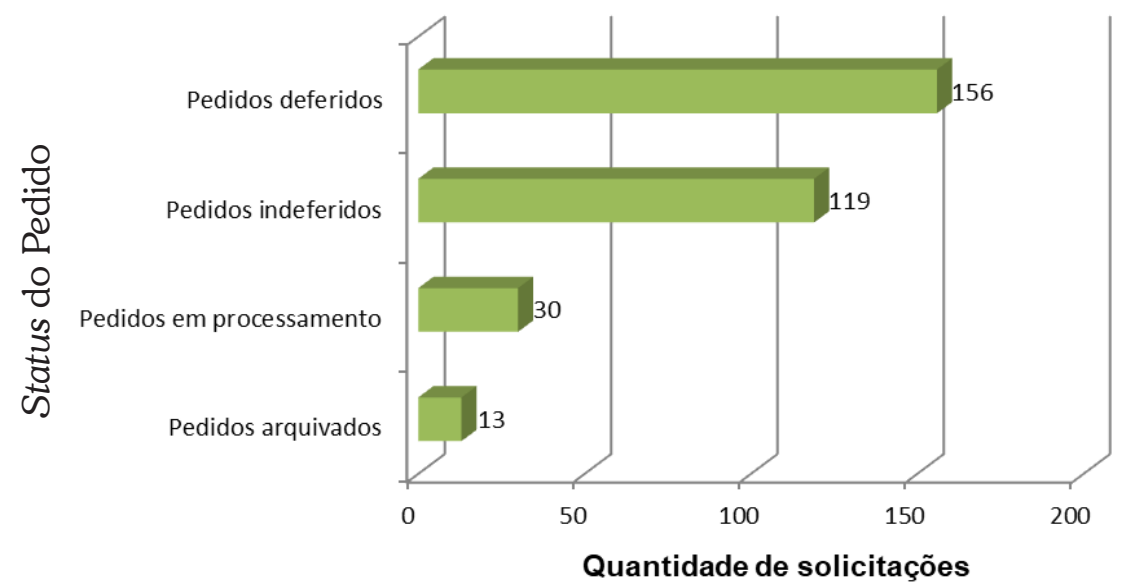

Fonte: Elaborada pelos autores deste artigo com base em dados extraídos do INPI (2019) 
De acordo com os resultados apresentados na Figura 3, dos 318 depósitos na categoria, quase metade $(49,1 \%)$ foram deferidos, totalizando 156 tecnologias patenteáveis em gerenciamento de resíduos. Entre as demais solicitações dessa categoria encontram-se 119 pedidos indeferidos (37,4\%), 30 em processamento $(9,4 \%)$ e 13 solicitações arquivadas $(4,1 \%)$.

Cabe ressaltar que dos 274 pedidos deferidos em todas as categorias (vide Figura 1), 156 deles foram na categoria de gerenciamento de resíduos, dado que representa $56,9 \%$ dos pedidos deferidos pelo Programa Patentes Verdes do INPI.

Dada a expressividade dos resultados em deferimento de tecnologias verdes na categoria de gerenciamento de resíduos, foi analisada a evolução anual do número de concessões de patentes na categoria a partir da implementação do Programa Patentes Verdes, conforme se demonstra a seguir, na Figura 4.

Figura 4 - Evolução anual da concessão de Patentes Verdes em Gerenciamento de Resíduos pelo INPI

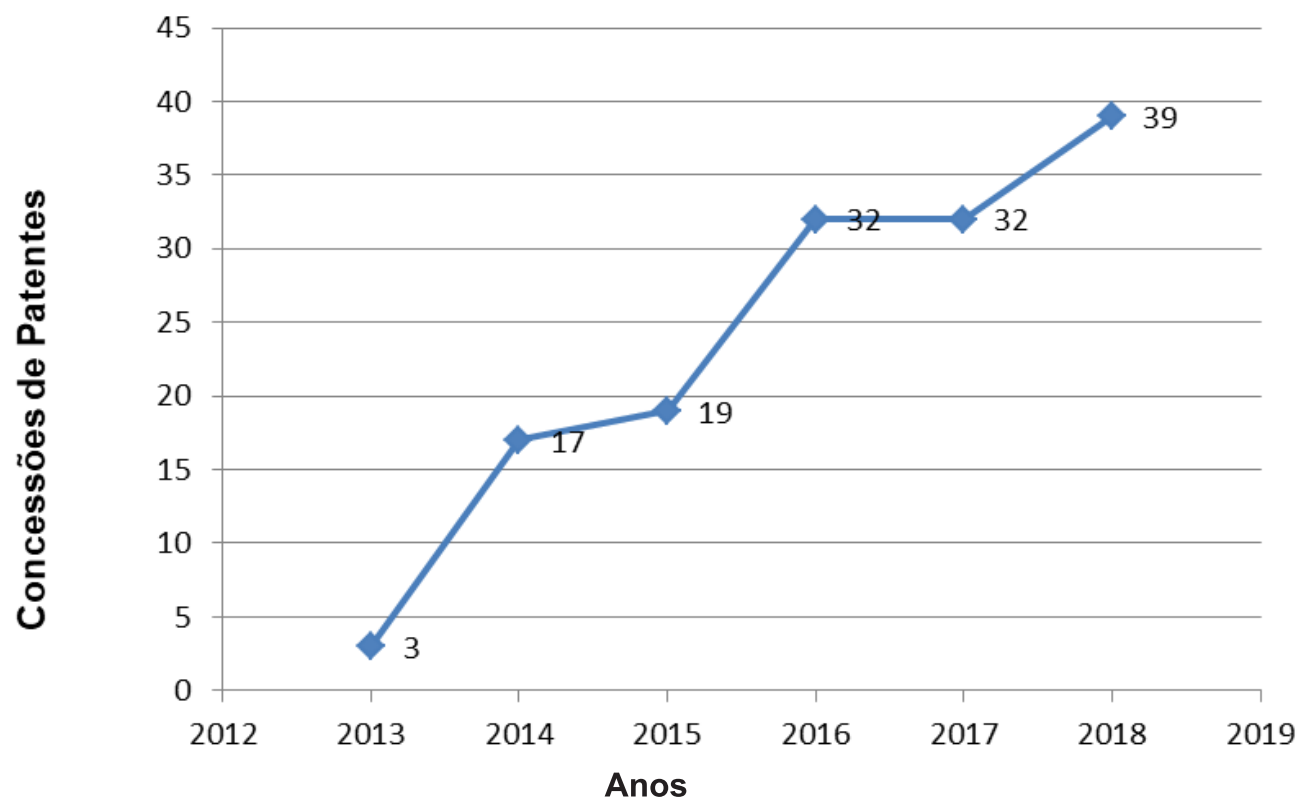

Fonte: Elaborada pelos autores deste artigo com base em dados extraídos do INPI (2019)

Os resultados apresentados na Figura 4 representam o avanço do desenvolvimento de tecnologias verdes em gerenciamento de resíduos ao longo de seis anos de atuação do Programa Patentes Verdes no Brasil. Verifica-se como período de maior crescimento de um ano para outro em concessão de patentes, o intervalo entre 2013 e 2014, com um salto de 3 patentes concedidas em 2013 para 17, em 2014. Este crescimento pode ser correlacionado com o tempo médio para concessão dessas patentes verdes pelo INPI que, de acordo com a amostra, fica em torno de 21 meses, identificando-se na análise como menor tempo para concessão de uma patente 5 meses e, como maior tempo, 60 meses.

Contudo, o resultado mais contundente foi em 2018 com 39 patentes verdes concedidas na categoria de gerenciamento de resíduos, possibilitando fazer uma análise prévia positiva acerca do desenvolvimento tecnológico nessa categoria, tendo em vista o crescimento gradativo ao longo dos anos, mantendo-se estagnado apenas no período de 2016 a 2017. 
Importante frisar, que de acordo com os resultados obtidos, até maio de 2019, período em em que os dados foram analisados, 10 patentes foram concedidas neste ano e mais 4 já foram deferidas, porém, até 10 de maio de 2019, as cartas patentes ainda não haviam sido emitidas.

Ainda, por meio da análise das 156 Patentes Verdes deferidas em gerenciamento de resíduos, o estudo permitiu classificar os depositantes em residentes, quando a origem do pedido é brasileira e, não residentes, quando a origem do pedido é estrangeira. Assim foram 119 pedidos residentes e apenas 37 pedidos não residentes, conforme representado na Figura 5.

Figura 5 - Patentes Verdes deferidas na categoria Gerenciamento de Resíduos por residentes e não residentes

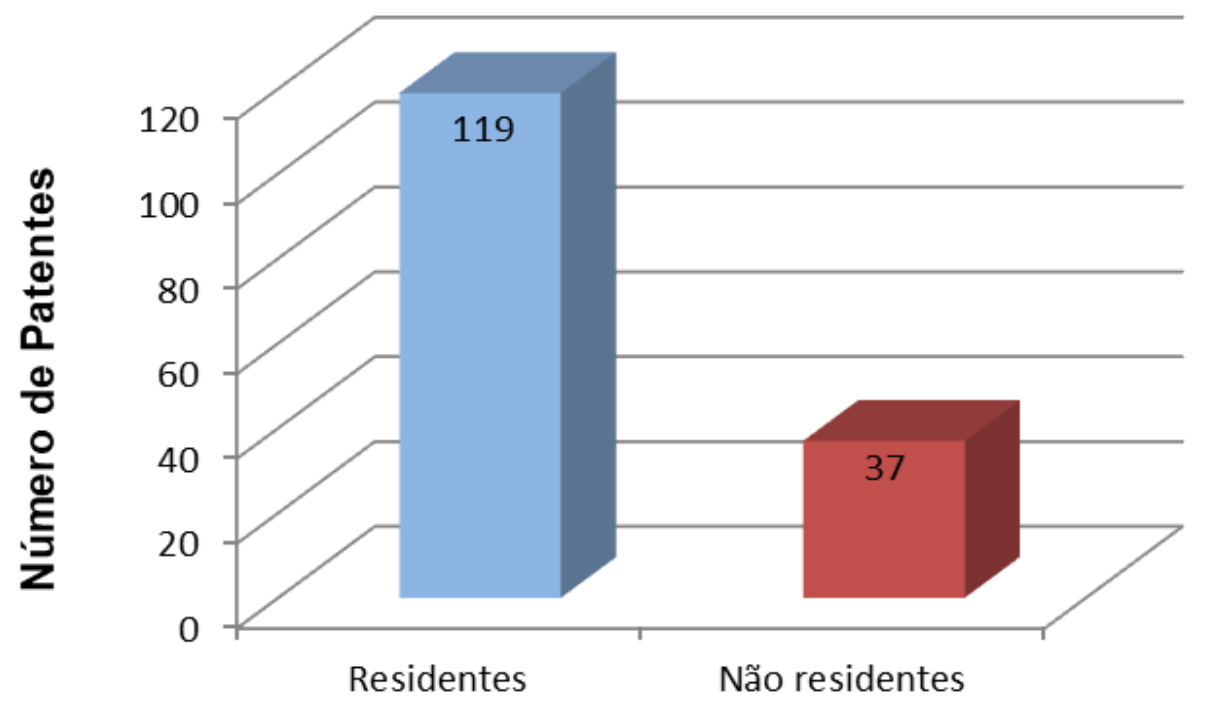

Fonte: Elaborada pelos autores deste artigo com base em dados extraídos do INPI (2019)

A origem das patentes determinou que o número de tecnologias deferidas na categoria de gerenciamento de resíduos por residentes foi superior ao de não residentes. Resultados estatísticos como esses demonstram, além da aceitação do Programa Patentes Verdes, que os efeitos positivos do incentivo ao desenvolvimento tecnológico sustentável em âmbito nacional já podem ser notados. Ao passo que a identificação de tecnologias de origem estrangeira (não residentes) evidencia a existência de outros 15 países com interesse no mercado brasileiro.

Dentre os países estrangeiros com pedidos deferidos na categoria de gerenciamento de resíduos, o de maior incidência foi Estados Unidos com 18 pedidos deferidos, seguido da Holanda com 3 pedidos deferidos e, na sequência, Alemanha, França e Reino Unido com 2 pedidos deferidos cada um. Os demais países que apareceram na análise apresentaram apenas um pedido deferido: Argentina, Canadá, China, Ilhas Cayman, Japão, Luxemburgo, Noruega, Nova Zelândia, Suécia e Suíça.

Retomando a análise das tecnologias deferidas depositadas por residentes, foi possível identificar em quais regiões e estados brasileiros estão sendo desenvolvidas inovações verdes em gerenciamento de resíduos, conforme se observa no georreferenciamento da Figura 6. 
Figura 6 - Georreferenciamento das Patentes Verdes em Gerenciamento de Resíduos no Brasil

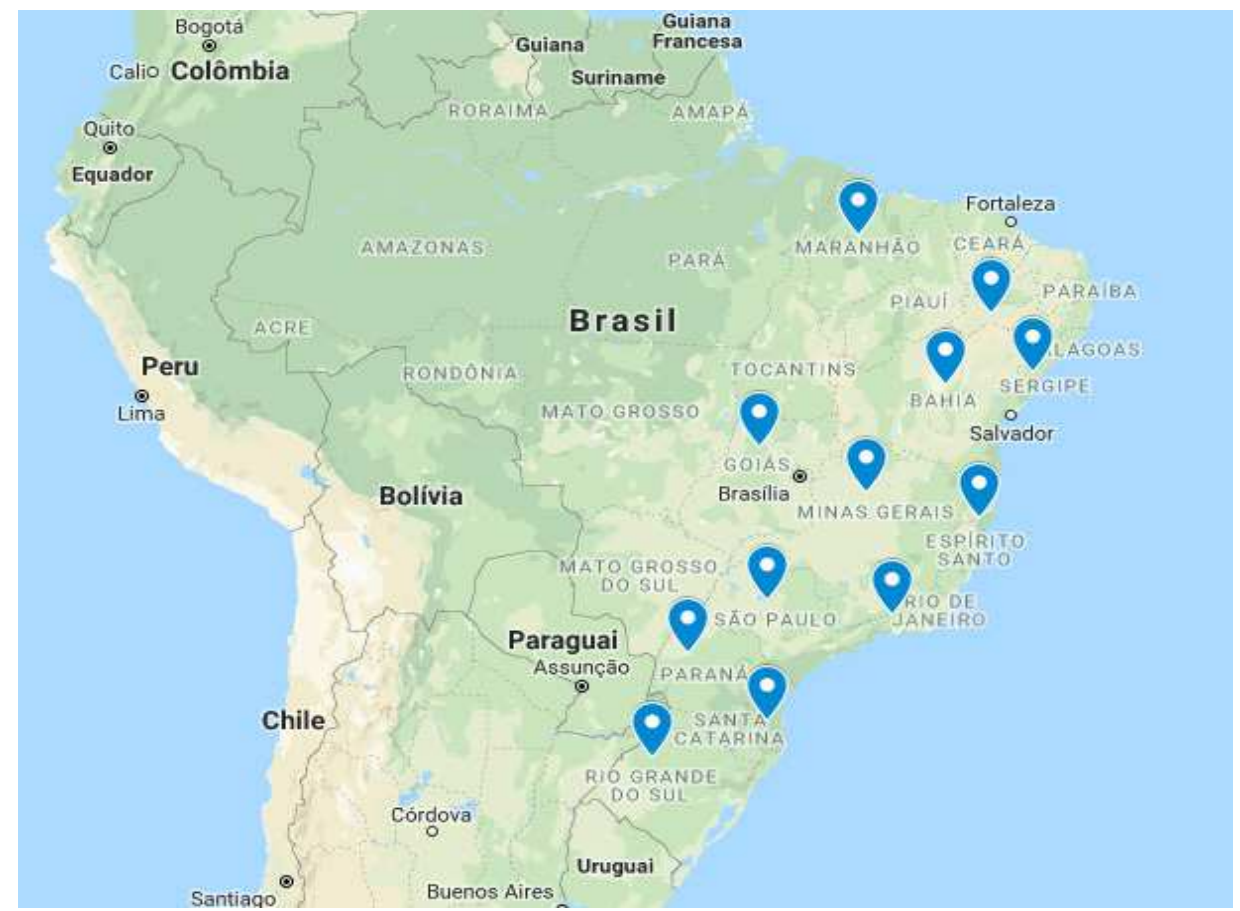

Fonte: Elaborada pelos autores deste artigo a partir de dados cartográficos do Google (2019)

Algumas regiões brasileiras se sobrepõem a outras em se tratando de desenvolvimento tecnológico. Por meio da Figura 6 também é possível verificar essa disparidade quando se analisa territorialmente o desenvolvimento de tecnologias verdes em gerenciamento de resíduos, e vê-se que, de acordo com a pesquisa, a região Norte ainda não apresenta nenhuma tecnologia patenteável desenvolvida nesta categoria. Já na região Centro-Oeste apenas o estado de Goiás apresenta resultados neste sentido; com maior destaque que as regiões anteriores, na região Nordeste verifica-se quatro estados com tecnologias verdes deferidas na categoria, mas a predominância geográfica ocorre nas regiões Sul e Sudeste, em que todos os estados apresentam tecnologias deferidas em gerenciamento de resíduos.

Ao se analisar o número de pedidos deferidos por residentes, ainda foi possível estabelecer um ranking levando-se em consideração a quantidade de tecnologias desenvolvidas por cada estado brasileiro na categoria em análise, conforme se verifica adiante na Tabela 1.

Tabela 1 - Ranking de Patentes Verdes em Gerenciamento de Resíduos por estados brasileiros

$\begin{array}{ccc} & \text { Estado } & \text { Quantidade DE PATENTES } \\ \mathbf{1}^{\mathbf{0}} & \text { São Paulo (SP) } & 43 \\ \mathbf{3}^{\mathbf{o}} & \text { Rio Grande do Sul (RS) } & 17 \\ \mathbf{4}^{\mathbf{0}} & \text { Minas Gerais (MG) } & 12 \\ & \text { Rio de Janeiro (RJ) } & 9 \\ \mathbf{5}^{\mathbf{0}} & \text { Santa Catarina (SC) } & 9 \\ \mathbf{6}^{\mathbf{0}} & \text { Bahia (BA) } & 8 \\ \mathbf{7}^{\mathbf{0}} & \text { Espirito Santo (ES) } & 6 \\ \end{array}$




\section{EsTADO}

Quantidade DE PATENTES

$\begin{array}{cc} & \text { Maranhão (MA) } \\ \mathbf{8}^{\mathbf{0}} & \text { Pernambuco (PE) } \\ & \text { Sergipe (SE) }\end{array}$

TOTAL 119

Fonte: Elaborada pelos autores deste artigo com base em dados extraídos do INPI (2019)

Mais uma vez destacam-se as regiões Sul e Sudeste com estados que ocupam as primeiras colocações em número de patentes, com ênfase para a região Sudeste que, além de apresentar três dos seus quatro estados nas quatro primeiras colocações, ocupa também o primeiro lugar com o estado de São Paulo, com 43 patentes deferidas, representando uma diferença expressiva em número de patentes quando comparado com os demais estados brasileiros que compõem a amostra, de modo que apenas as tecnologias desenvolvidas no estado de São Paulo equivalem a 36,1\% dos pedidos deferidos em gerenciamento de resíduos por residentes.

Na região Sul destaca-se o estado do Rio Grande do Sul com 17 pedidos deferidos, ocupando a segunda colocação nacional, e na região Nordeste, o estado com maior número de pedidos deferidos é a Bahia, com 8 pedidos deferidos na categoria, o que representa $72,7 \%$ dos pedidos deferidos nesta região, uma vez que os demais estados nordestinos apresentaram apenas um pedido deferido para cada um, conforme exposto na Tabela 1.

Voltando para a análise dos 156 documentos de Patentes Verdes deferidas em gerenciamento de resíduos, também foi possível identificar o perfil dos titulares por meio de consulta aos dados do campo "Nome do Titular" em cada documento de patente. Assim, os titulares foram categorizados em: Centro de Pesquisa, Empresa, Pessoa Física e Universidade, conforme percentual por perfil de titulares ilustrado na Figura 7.

Figura 7 - Perfil dos titulares de Patentes Verdes deferidas pelo INPI na categoria Gerenciamento de Resíduos

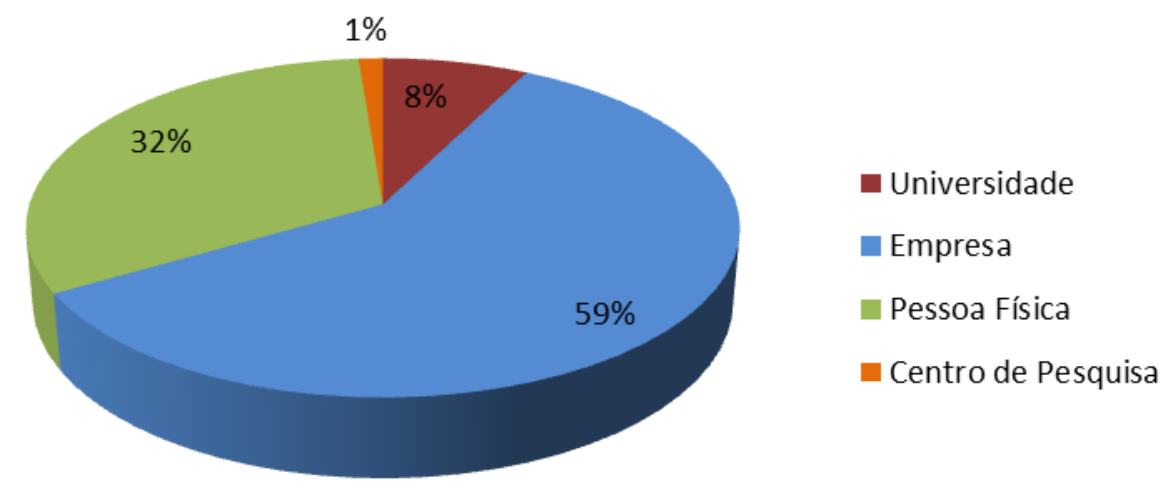

Fonte: Elaborada pelos autores deste artigo com base em dados extraídos do INPI (2019)

O estudo dos indicadores referentes ao perfil dos titulares evidencia como depositante mais comum das Patentes Verdes em Gerenciamento de Resíduos as empresas. São elas responsáveis por $59 \%$ das tecnologias verdes desenvolvidas nesta categoria, seguidas das pessoas físicas (inventores independentes), que representam $32 \%$ dos titulares. Na sequência vêm as universidades com uma representação de $8 \%$ e os centros de pesquisa com $1 \%$. 
Nesse contexto, Santos et al. (2017) já constatou a tímida mobilização de esforços do aparato público de Ciência, Tecnologia e Inovação no Brasil em prol da pesquisa e do desenvolvimento das tecnologias verdes.

Contudo, é importante ressaltar que das 156 tecnologias deferidas, três foram desenvolvidas em parceria, sendo uma delas entre empresa e universidade e as outras entre empresa $e$ pessoa física; desta forma, para efeitos da análise acima apresentada, essas tecnologias foram contabilizadas duas vezes, uma para cada perfil.

Partindo para a identificação dos tipos de tecnologias limpas que estão em desenvolvimento na categoria de gerenciamento de resíduos, utilizou-se o número de Classificação IPC. Assim, de acordo com a Classificação IPC, que consta na folha de rosto de cada documento de patente, foi possível distribuir as 156 patentes deferidas em oito grandes áreas do conhecimento humano de acordo com a respectiva seção em que estão classificadas, conforme se observa na Figura 8.

Figura 8 - Distribuição das Patentes Verdes em Gerenciamento de Resíduos por área de classificação internacional

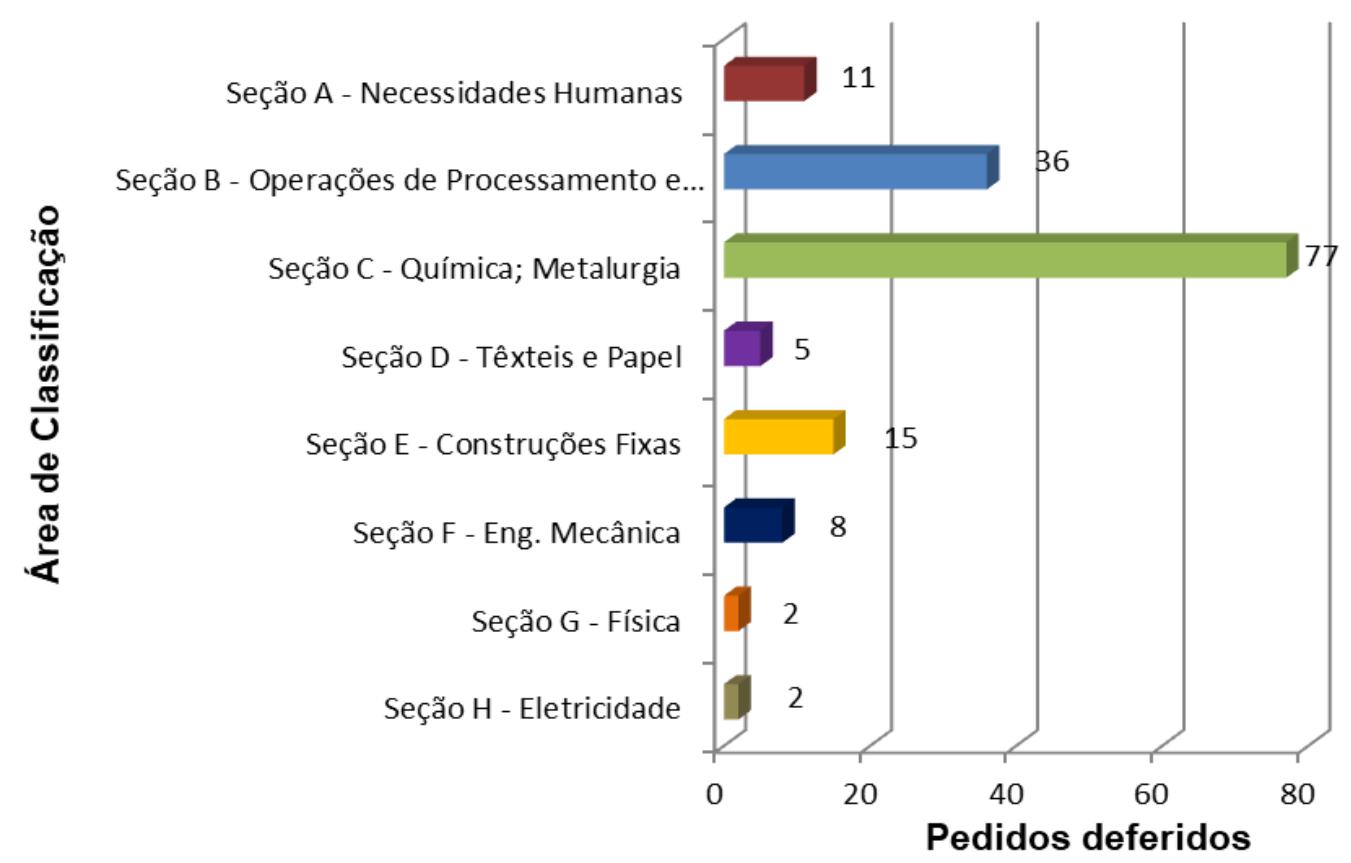

Fonte: Elaborada pelos autores deste artigo com base em dados extraídos do INPI (2019)

Ressalta-se que em algumas ocasiões foram identificadas em um único documento de patente uma variedade de classificações. Assim, para efeito da análise acima apresentada foi levada em consideração apenas a classificação principal em cada documento.

Portanto, a partir dos dados referentes às áreas, constatou-se na Figura 8 que o maior número de patentes está classificado na seção C - Química e Metalurgia com 77 pedidos de patentes deferidas, o equivalente a 49,3\% dos pedidos deferidos em gerenciamento de resíduos, seguido da seção B - Operações de Processamento e Transporte com 36 tecnologias deferidas (23\%) e da seção E - Construções Fixas com 15 patentes (9,6\%). As demais seções juntas representam $18,1 \%$ dos pedidos deferidos.

Por ocasião dos resultados obtidos na seção $\mathrm{C}$, foram identificadas tecnologias deferidas em 13 classes nesta área. Desse modo, foram verificadas as classes com mais repetições na seção 
C, conforme é possível observar na Tabela 2 , em que consta o número de vezes em que cada classe foi encontrada na amostra.

Tabela 2 - Incidência de classes encontradas na seção C

\begin{tabular}{|c|c|}
\hline Classificação & INCIDÊNCIA \\
\hline \multicolumn{2}{|l|}{ QUÍMICA } \\
\hline C01 - Química inorgânica & 3 \\
\hline C02 - Tratamento de água, de águas residuais, de esgotos ou de lamas e lodos & 18 \\
\hline C04 - Cimento; concreto; pedra artificial; cerâmica; refratários & 3 \\
\hline C05 - Fertilizantes; sua fabricação & 8 \\
\hline C07 - Química orgânica & 6 \\
\hline $\begin{array}{l}\text { C08 - Compostos macromoleculares orgânicos; sua preparação ou } \\
\text { seu processamento químico; composição baseada nos mesmos }\end{array}$ & 5 \\
\hline $\begin{array}{l}\text { C09 - Corantes; tintas; polidores; resinas naturais; adesivos; composições não } \\
\text { abrangidos em outros locais; aplicações de materiais não abrangidos em outros locais }\end{array}$ & 1 \\
\hline $\begin{array}{l}\text { C10 - Indústrias do petróleo, do gás ou do coque; gases técnicos } \\
\text { contendo monóxido de carbono; combustíveis; lubrificantes; trufa }\end{array}$ & 12 \\
\hline $\begin{array}{l}\text { C11 - Óleos animais ou vegetais, gorduras, substâncias graxas ou } \\
\text { ceras; ácidos graxos derivados dos mesmos; detergentes; velas }\end{array}$ & 1 \\
\hline $\begin{array}{l}\text { C12 - Bioquímica; cerveja; álcool; vinho; vinagre; microbiologia; } \\
\text { enzimologia; engenharia genética ou de mutação }\end{array}$ & 14 \\
\hline \multicolumn{2}{|l|}{ METALURGIA } \\
\hline C21 - Metalurgia do ferro & 2 \\
\hline $\begin{array}{l}\text { C22 - Metalurgia; ligas ferrosas ou não ferrosas; } \\
\text { tratamento de ligas ou materiais não ferrosos }\end{array}$ & 2 \\
\hline C25 - Processos eletrolíticos ou eletroforéticos; aparelhos para este fim & 2 \\
\hline
\end{tabular}

Fonte: Elaborada pelos autores deste artigo com base em dados extraídos do INPI (2019)

De acordo com a Tabela 2, vê-se que das 77 tecnologias deferidas na seção C apenas 6 enquadram-se em metalurgia, enquanto que a química apresenta os maiores resultados, de modo que esta quantidade de tecnologias deferidas na área química possivelmente está relacionada com a conexão existente entre as atividades químicas e as mais diversas cadeias produtivas.

Para Farias e Fávaro (2011, p. 1.089), "a indústria química participa ativamente de quase todas as cadeias produtivas e complexos industriais, inclusive serviços e agricultura, desempenhado um papel de destaque nas diversas atividades econômicas do mundo", corroborando, portanto, com o entendimento de que o cruzamento com vários outros setores ocasiona a amplitude no desenvolvimento de tecnologias nesta área.

Ademais, cabe destacar que a Classe com maior incidência de resultados foi a "C02 - Tratamento de água, de águas residuais, de esgotos ou de lamas e lodos" em que estão inseridas as tecnologias relativas ao que está descrito no título retro, com um total de 18 pedidos de patentes deferidos. As tecnologias desenvolvidas nessa Classe têm relação direta com a subcategoria de controle de poluição da água descrita na categoria de gerenciamento de resíduos do Inventário Verde da OMPI. 
Diante da análise dos resultados do Programa Patentes Verdes, é possível traçar tendências e trajetórias de pesquisas em desenvolvimento que contribuam para o mapeamento de tecnologias limpas no Brasil e, nesta pesquisa em específico, contribuam também como fator determinante para alcance de objetivos da PNRS.

\section{Considerações Finais}

Na perspectiva de investigar o desenvolvimento de tecnologias verdes relativas ao gerenciamento de resíduos como auxílio ao cumprimento das diretrizes da PNRS, a pesquisa pautou-se em analisar informações tecnológicas contidas em documentos de patentes deferidas e relacionadas ao gerenciamento de resíduos a partir dos resultados do Programa Patentes Verdes do INPI.

Assim, foi realizado um estudo de cunho exploratório na base de patentes do INPI com vistas a verificar a aplicabilidade da categoria de gerenciamento de resíduos ao programa, bem como identificar atributos relevantes dos pedidos de patente verde nesta categoria.

Dessa forma, a pesquisa identificou que, dentre as cinco categorias de tecnologias verdes contempladas pela Resolução n. 175/2016 do INPI, a de gerenciamento de resíduos apresenta o maior número de pedidos e deferimentos de patentes, representando mais da metade dos pedidos deferidos pelo Programa Patentes Verdes no período de abril de 2012 a abril de 2019.

Nesse sentido, o artigo $7^{\circ}$, IV da Lei n. 12.305/2010, ao estabelecer como um dos objetivos da PNRS o desenvolvimento e aprimoramento das tecnologias limpas como forma de mitigar os impactos ambientais, ganha efetividade com o Programa Patentes Verdes, diante da notoriedade dos resultados apresentados em desenvolvimento de tecnologias verdes na categoria de gerenciamento de resíduos.

Entretanto, a pesquisa constatou pouca incidência das universidades e dos centros de pesquisa no desenvolvimento dessas tecnologias, fato que demonstra o distanciamento entre o setor produtivo e estas instituições, verificando-se na análise apenas uma única situação em que a tecnologia foi desenvolvida por meio de parceria entre universidade e empresa.

Em contrapartida, as empresas e os inventores independentes apresentam resultados positivos e crescentes no desenvolvimento de tecnologias verdes voltadas para o gerenciamento de resíduos, com destaque para as tecnologias classificadas na área química.

Portanto, por meio da análise do perfil dos titulares, da origem e evolução anual da concessão de Patentes Verdes em Gerenciamento de Resíduos é possível prospectar uma expectativa de crescimento anual com interesse nestas tecnologias por parte de empresas e inventores nacionais localizados, principalmente, nas regiões Sul e Sudeste do país, com maior incidência no estado de São Paulo.

Estudos prospectivos em documentos de patentes como este apresentam grande relevância para a formulação de um cenário de tendências em desenvolvimento tecnológico sustentável, uma vez que, em se tratando de patenteamento, a informação é tida como recurso fundamental e imprescindível. Todavia, esta pesquisa não exaure a necessidade por outros estudos com este mesmo direcionamento, sugerindo-se que sejam realizadas pesquisas futuras, com ênfase em outras categorias verdes, também em outras bases de dados de patentes, ou até mesmo que possibilitem mensurar a transferência de tecnologia verde no mercado. 


\section{Referências}

BARBIERI, J. C. Políticas públicas indutoras de inovações tecnológicas ambientalmente saudáveis nas empresas. RAP - Revista de Administração Pública, Rio de Janeiro, v. 31, n. 2, p. 135-152, mar./abr. 1997.

BARBOSA, D. B. Uma Introdução à Propriedade Intelectual. Rio de Janeiro: Lumen Juris, 2010.

BRASIL, Lei n. 6.938 de 31 de agosto de 1981. Dispõe sobre a Política Nacional do Meio Ambiente, seus fins e mecanismos de formulação e aplicação, e dá outras providências. Brasília, DF: Casa Civil. Disponível em: http://www.planalto.gov.br/ccivil_03/Leis/L6938.htm. Acesso em: 22 maio 2019.

BRASIL, Lei n. 12.187 de 29 de dezembro de 2009. Institui a Política Nacional sobre Mudança do Clima - PNMC e dá outras providências. Brasília, DF: Casa Civil. Disponível em: http://www. planalto.gov.br/ccivil_03/_ato2007-2010/2009/lei/112187.htm. Acesso em: 22 maio 2019.

BRASIL. Lei n. 12.305 de 02 de agosto de 2010. Institui a Política Nacional de Resíduos Sólidos; altera a Lei no 9.605 de 12 de fevereiro de 1998; e dá outras providências. Brasília, DF: Casa Civil. Disponível em: http://www.planalto.gov.br/ccivil_03/_ato2007-2010/2010/lei/112305.htm. Acesso em: 22 maio 2019.

BRASIL. Lei n. 12.527 de 18 de novembro de 2011. Regula o acesso a informações previsto no inciso XXXIII do art. 5o, no inciso II do § 3o do art. 37 e no § 2o do art. 216 da Constituição Federal; altera a Lei no 8.112, de 11 de dezembro de 1990; revoga a Lei no 11.111, de 5 de maio de 2005, e dispositivos da Lei no 8.159, de 8 de janeiro de 1991; e dá outras providências. Brasília, DF: Casa Civil. Disponível em: <http://www.planalto.gov.br/ccivil_03/_ato2011-2014/2011/lei/ 112527.htm Acesso em: 20 jul. 2019.

COMISSÃO MUNDIAL SOBRE MEIO AMBIENTE E DESENVOLVIMENTO. Nosso futuro comum. (1988). Rio de Janeiro: Fundação Getúlio Vargas, 1991.

FARIAS, L. A.; FÁVARO, D. T. Vinte anos de química verde: conquistas e desafios. Química Nova, São Paulo, v. 34, n. 6, p. 1.089-1.093, 2011.

GARCIA, J. C. R. Patente gera patente? Transinformação, Campinas, v. 8, n. 3, p. 213-223, set./ dez. 2006.

GARCIA, J. C. R. Usar ou não usar a patente: eis a questão! In: GIANNASI-RAIMEN, M. J.; CARELLI, A. E. Recursos informacionais para compartilhamento da informação: redesenhando acesso, disponibilidade e uso. Rio de Janeiro: E-papers, 2007. p. 47-71.

GIL, A. C. Métodos e técnicas de pesquisa social. 5. ed. São Paulo: Atlas, 1999.

INPI. Classificação de patentes. 2019. Disponível em: http:/www.inpi.gov.br/menu-servicos/ patente/classificacao-de-patentes. Acesso em: 3 jun. 2019.

INPI. Resolução n. 175, de 5 de novembro de 2016. Disciplina o exame prioritário de pedidos de "Patente Verde". Disponível em: file://C:/Users/RH\%20CCRei/Downloads/Resoluon1752016_ Patentesverdes_21112016julio_docx.pdf. Acesso em: 1º de mar. 2019.

INPI. Resolução n. 283, de 02 de abril de 2012. Disciplina o exame prioritário de pedidos de Patentes Verdes, no âmbito do INPI, os procedimentos relativos ao Programa Piloto relacionado ao tema e dá outras providências. Disponível em: http://ld2.ldsoft.com.br/siteld/arq_avisos/ Comunicados_Patentes1_RPI_2154.pdf. Acesso em: $1^{\circ}$ mar. 2019. 
MARICATO, J. M.; NORONHA, D. P.; FUJINO, A. Análise bibliométrica da produção tecnológica em biodiesel: contribuições para uma política em CT\&I. In: Anais [...] do ENCONTRO NACIONAL DE PESQUISA EM CIÊNCIA DA INFORMAÇÃO, 2008, São Paulo. São Paulo, 2008. Disponível em: http://www.ancib.org.br/pages/anais-do-enancib.php. Acesso em: 18 jul. 2019.

MENEZES, C. C. N.; SANTOS, S. M.; BORTOLI, R. Mapeamento de tecnologias ambientais: um estudo sobre Patentes Verdes no Brasil. GeAS - Revista de Gestão Ambiental e Sustentabilidade, São Paulo, v. 5, n. 1, p. 18-32, jan./abr. 2016.

NARIN, F; BREITZMAN, A; THOMAS, P. Using patent citation indicators to manage a stock portfolio. Handbook of Quantitative Science and Technology Research: the use of publication and patent statistics in studies of S\&T systems. Dordrecht: Kluwer Academic Publishers, 2005. cap. 25 , p. 553-568.

PEREIRA, C. O fluxo e as dimensões socioespacial e socioinstitucional do conhecimento em Ciência, Tecnologia \& Inovação: um estudo patentiométrico da produção tecnológica da Unicamp. Dissertação (Mestrado em Ciência da Informação) - Pontifícia Universidade Católica, Campinas, São Paulo, 2008.

SÁNCHEZ, M. V. G. Patentometria: herramienta para el análisis de oportunidades tecnológicas. Tese de Doutorado em Gerência da Información Tecnológica. Cuba: Facultad de Economia, Universidade de La Habana. 1999.

SANTOS, N. Patentes Verdes: Mecanismo de desenvolvimento sustentável. Rio de Janeiro: Lumen Juris, 2016.

SANTOS, R. N. M.; DOMINIQUE, A. P.; SÁNCHEZ, M. L. L.; CASADO, E. S. Tecnologias verdes para um mundo autossustentável: um olhar sobre Brasil e Espanha. Em Questão, Porto Alegre, v. 23, n. 2, p. 277-294, maio/ago. 2017.

WIPO. International Patent Classification (IPC). Disponível em: https://www.wipo.int/ classifications/ipc/en/. Acesso em: 18 jul. 2019.

WIPO. STANDARD ST.9: recommendation concerning bibliographic data on and relating to patents and SPCs. Handbook on industrial property information and documentation, Apr. 2013.

ZANELLA, L. C. H. Metodologia da pesquisa. 2. ed. Florianópolis: Universidade Federal de Santa Catarina, 2011.

ZIKMUND, W. G. Business research methods. 5. ed. Fort Worth, TX: Dryden, 2000.

\section{Sobre os Autores}

\section{Luiz Nunes Filho}

E-mail: luiznunes.alipb@gmail.com

Advogado e Mestre pelo Programa de Pós-Graduação em Propriedade Intelectual e Transferência de Tecnologia para Inovação da Universidade Federal de Pernambuco.

Endereço profissional: Rua, José Crispim, n. 675, Bairro: Monte Castelo, Patos, PB. CEP: 58707-060. 


\section{Raimundo Nonato Macedo dos Santos}

E-mail: rnmacedo@uol.com.br

Professor na Universidade Federal de Pernambuco e Doutor em Information Stratégique Et Critique Veille Technol na Université Paul Cézanne Aix Marseille III.

Endereço profissional: Universidade Federal de Pernambuco, Centro de Artes e Comunicação, Departamento de Ciência da Informação. Av. da Arquitetura, s/n, Campus Universitário, Recife, PE. CEP: 50740-550. 